\title{
Esbozo de método para el estudio del siglo xx e inicios
}

Sketch of method for the study of the twentieth century and the beginning of the twenty-first

Alejandro Dabat **

\section{Introducción}

Por la complejidad y la extensión del tiempo histórico a tratar y la dispersión teórica y metodológica que hoy aqueja a las ciencias histórico-sociales y el retraso de las ciencias sociales críticas frente a los fenómenos actuales, comenzaremos por definir los principales conceptos e instrumentos metodológicos a usar en este esbozo, a partir de cinco breves secciones: ${ }^{1}$ a) el carácter sistémico-estructural y dinámico del capitalismo industrial (o moderno) como punto de partida del análisis; b) los criterios de localización espacial-territoriales del mismo; c) las concepciones de periodización a largo plazo a utilizar; d) la práctica social, sus diversos planos (movimientos sociales de distinto tipo) y sus métodos de lucha; e) la relación en los movimientos sociopolítico en sus diversos planos y el de los métodos de lucha de los mismos y f) el de la relación entre la política y sus diversos planos y espacios y los fenómenos de la guerra.

\section{A. Aspectos sistémico-estructurales}

Siguiendo a Marx, Gramsci, a otros economistas y sociólogos clásicos y contemporáneos no marxistas o a las aportaciones metodológicas re-

1 Para un análisis amplio de los tres primeros puntos, sobre todo del segundo y el tercero, Alejandro Dabat, Capitalismo mundial y capitalismos nacionales, Cuernavaca, Morelos México, FCE, 1994, pp. 1-30; y El Mundo y las Naciones, Cuernavaca, Morelos México, CRIM-UNAM, 1993, pp. 109-198, en conjunto con parte de la bibliografía citada en la nota siguiente.
* Este artículo forma parte del proyecto de investigación Las grandes etapas del desarrollo del capitalismo con financiamiento del PAPIIT-DGAPA, IN301816.

**Investigador Titular C (Académico). Área de adscripción; Economía del Conocimiento y Desarrollo. Instituto de Investigaciones Económicas, UNAM

cientes para el estudio de los sistemas complejos (Bunge, Mario, 2004; García, Rolando 2006 etc.), concebiremos al capitalismo industrial moderno, como un sistema complejo, dinámico y abierto, integrado en lo fundamental por cuatro diferentes planos, niveles o esferas de reproducción social, interdependiente del nombre que se les adjudique (Marx, 1999, Bourdieu 2012).

Tales niveles, deben diferenciarse y relacionarse analíticamente entre sí, para la adecuada comprensión de la complejidad de los procesos históricos característicos del sistema, ${ }^{2}$ de su unidad sistémica y de las particularidades concretas del mismo en una época y un espacio territorial determinado. La determinación de los niveles es importante, no solo por las diferentes funcio-

2 C. Marx 1999: Capitulo XIII "Maquinaria y gran industria"; C. Marx 1984: Cuaderno 5 "Las maquinas"; A. Gramsci 1975; Werner Sombart 1984: 91-92 y 124125; Max Weber 1944: 170-240; Pierre Bourdieu 2012; Pérez 1985: 441-463; Marshall Berman 2001: 119-128; y Otto Bauer 1979. 
nes que ellos cumplen en la reproducción social, sino porque cada uno de ellos supone tanto un determinado tipo de sujetos y objetivos sociales, como de combinaciones distintas de los sujetos sociales con objetos inertes (materiales, instrumentos etc.) propios de ese campo, así como de técnicas específicas para actuar en el mismo. Por ello se hace necesario considerar brevemente la composición básica de esos niveles:

A1) El primer nivel es la base tecno-económica del sistema, ${ }^{3}$ que está formada por cinco componentes fundamentales: a) Una infraestructura tecnológica dinámica de base mecánica (fabril y de condiciones generales de producción), que condiciona y modifica en conjunto de los demás niveles; b) Una economía de mercado y dineraria generalizada, de incorporación masiva de la tierra y el trabajo a la circulación mercantil; c) Una base de producción y reproducción de bienes y servicios, a partir de empresas capitalistas privadas y trabajo asalariado; d) una relación creciente con la ciencia; e) un sistema financiero de propiedad accionaria, crédito y especulación financiera; f) una regulación pública limitada y subordinada a la reproducción del capital. En conjunto, tales componentes constituyen una unidad dinámica en constante mutación, bajo la acción del cambio tecnológico, la composición del mercado y la competencia o el sector financiero, la acumulación de capital, el conflicto social o los tipos de tipo de intervención estatal.

A2) Conjuntamente, el sistema supone un entramado social clasista, crecientemente urbano e igualmente dinámico, basado en la propie-

3 Como componentes del sistema, estos son reconocidos con pocas diferencias por autores como Marx, Sombart o Veblen, siendo importantes los complementos de Schumpeter, Landes o Freeman y Pérez (ciencia y tecnología), Polanyi (amplio desarrollo de la mercantilización de la tierra y el trabajo); o de Hilferding y Minsky (Dinero, crédito y especulación financiera). dad privada capitalista y un trabajo asalariado libre de coerciones extraeconómicas (como la esclavitud o la servidumbre $\mathrm{u}$ otros factores de inmovilización de la fuerza trabajo). A partir de este primer tipo de relación social fundamental, una estructura social más amplia y compleja de múltiples sectores y grupos nucleados en instituciones civiles, originadas por la conjugación de la división y organización del trabajo y las relaciones de propiedad, poder y conocimiento, derivados de los restantes planos del sistema social, con las modificaciones particulares resultantes del conflicto social en sus distintas expresiones concretas (histórico-espaciales).

A3) A nivel institucional, una autoridad central clasista (Estado burgués) monopolizadora de la fuerza pública en un espacio territorial dado (nacional, protonacional, colonial o semicolonial según época y lugar) y relaciones sociopolíticas de fuerza, generadora de un orden jurídico coactivo de funcionamiento de la sociedad. Esta fuerza se organiza en torno a una cierta división de poderes, sistemas políticos relativamente representativos y aparatos burocráticos especializados; pero también a un doble tipo de funcionalidad que comprende tanto las funciones propiamente coercitivas de defensa del orden social establecido respaldadas por instituciones culturales (ideológicas), como medios sociales conformados de consenso social (legitimidad) sin los cuales no puede reproducirse el sistema en el largo plazo. Esto supone que la autoridad debe necesariamente, bajo pena de perder legitimidad, cumplir ciertas funciones sociales necesarias más amplias (nacionales) que relacionan al Estado con la sociedad civil de cada país.

A4) Finalmente tenemos una cultura "moderna" de marcados rasgos individualistas, que promueve la razón y el conocimiento científico-tecnológico, el pensamiento instrumental, la innovación, los valores urbanos o la idea de 


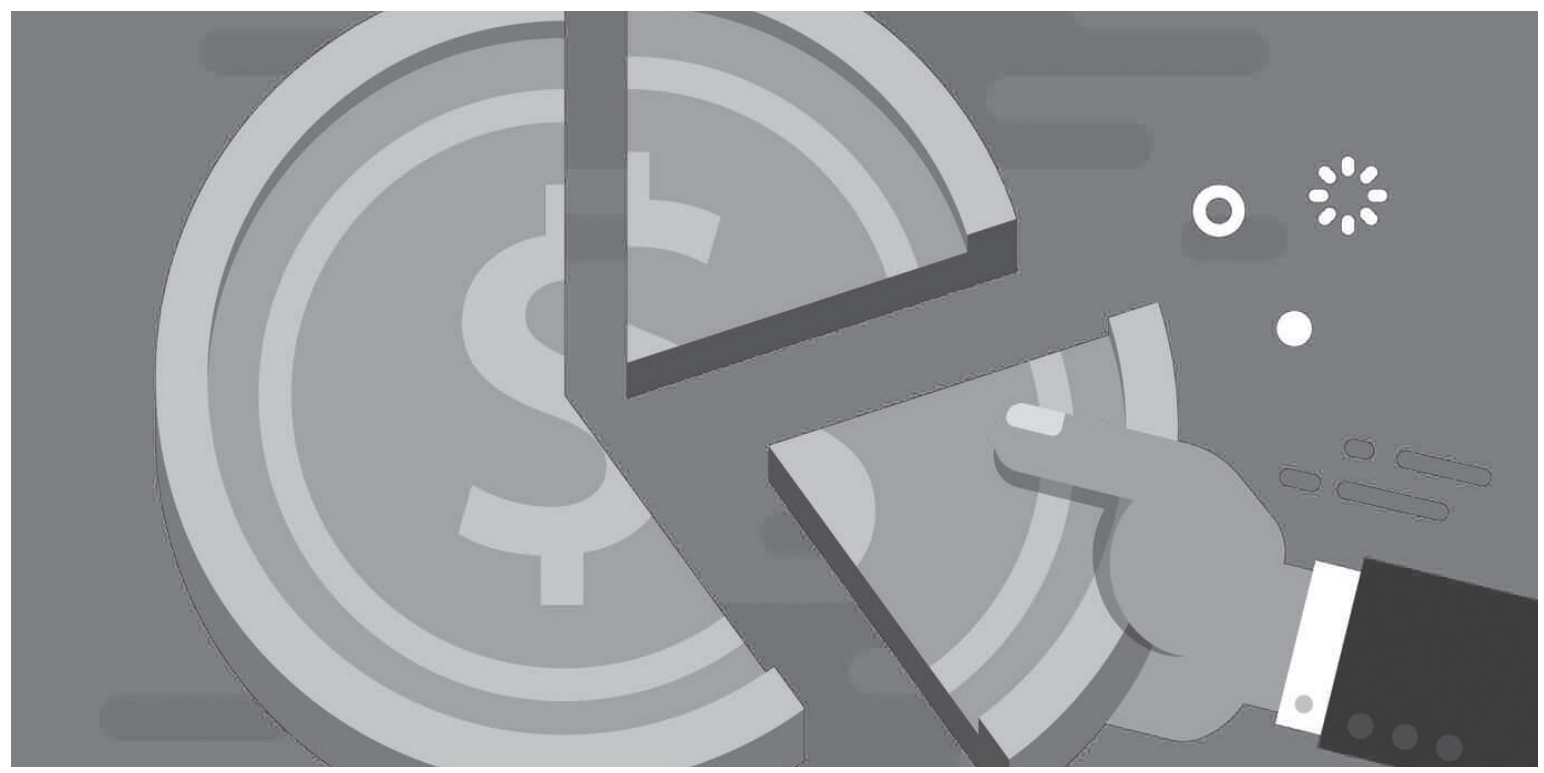

progreso y cambio, con contenidos tanto directamente relacionados (algunas de ellos) con el desarrollo de las fuerzas productivas y la valorización de la fuerza de trabajo, como con la reproducción del sistema social existente. A nivel espacial, la cultura tiene muy fuertes peculiaridades nacionales de cohesión interior diferentes para cada país (ver punto B1), que incluye tanto raíces populares como imposiciones de los grandes poderes dominantes (ideologías de clase, sector o fuerzas internacionales). Esto da lugar a diferentes puntos de vista sociales (superestructuras ideológicas), que expresan de cierta forma puntos de vista sociopolíticos y orientan la subjetividad social y el comportamiento de los grandes colectivos sociales.

En síntesis, la interacción de estos niveles constituye un sistema complejo que ha recibido diferentes nombres como "modo de producción específicamente capitalista” en Marx (diversos trabajos), "moderno sistema industrial” (Veblen, 2005) o, simplemente, "régimen capitalista" (Sombart, Ibid), aunque el nombre atribuido es mucho menos importante que la naturaleza del conjunto, interactividad y dinámica.

\section{B. Localización espacial-territorial}

Todo proceso y sistema social está localizado en espacios-territoriales con características específicas precisas (localización territorial, extensión de la misma, recursos naturales, población, infraestructura básica, capacidad productiva, condiciones socio-culturales, relaciones de poder o medio ambiente). Esto da lugar a la existencia de distintas escalas espaciales diversas de diferente tamaño (espacios rurales de diferentes características, localidades, ciudades, provincias, Estados nacionales o confederaciones o bloques de Estados etc.) relacionadas entre sí, ya sea por sus propiedades y funcionalidades dentro de un plano de la reproducción social, como de su jerarquía dentro de los distintos planos siempre dentro de una configuración específica y un periodo histórico determinado. ${ }^{4}$ En lo que hace específicamente al capitalismo industrial, el mismo

4 Sobre la relevancia de las determinaciones espaciales puede verse Harvey, 1990 (capitulo 1); Braudel, 1976, (primera parte); Massey (2012); Fernandez y Brandao (2010). Para la configuración espacial específica del capitalismo moderno, Dabat (1994, I, Introducción, 1994, pps 30-35). 
cuenta con una configuración espacial propia, también cambiante en las distintas etapas del sistema, que conjuga necesariamente tres tipos de escalas espaciales.

B1) Los múltiples capitalismos nacionales actuando dentro del medio competitivo del mercado mundial y las relaciones internacionales de fuerza, que también dan lugar a acuerdos y alianzas. Junto a ellos, los espacios políticoterritoriales no-nacionales (protonacionales o coloniales) o, desde el siglo xx, tampoco propiamente capitalistas en diferentes medidas (Unión Soviética, China, Cuba etc.) aunque operando, como anomalías conflictivas, dentro del mercado mundial capitalista y las relaciones internacionales de poder. En términos económicos generales, tal disparidad es el resultado espacial del desarrollo desigual del capitalismo internacional, de la relación de ello con los factores internacionales que veremos en el siguiente punto, o de la conjunción localizada de ambos factores en torno al llamado desarrollo desigual y combinado (Trotsky, 1985).

B2) El mercado mundial, como factor de integración de las entidades territoriales a la economía mundial (circulación de mercancías, capitales o personas), operando a partir de la división internacional del trabajo creada desde la revolución industrial (Dabat. 1994, pp. 185-186 y Anexo 1), en conjunción con los paradigmas dominantes en cada etapa del capitalismo (ver punto siguiente) y el desarrollo desigual y combinado de cada país (base nacional de integración). ${ }^{5}$ El nivel de desarrollo e independencia de cada país determinará el peso económico y político de los diferentes países. Las grandes potencias, resultarán de su tamaño, poderío industrial, financiero, cohesión interior, poder militar o incidencia internacional, con poder suficiente como para regir los destinos del mundo o partes de él (escala mundial o regional), sea por sí mismos o como parte de un sistema de alianzas (Kennedy Paul, 1994). En cuanto a las relaciones de dependencia entre los países, cabe diferenciar entre las resultantes de un tipo de superioridad tecnológica, productiva o financiera que conlleva imposiciones de hecho (o imperialistas a secas), de aquellas más fuertes establecidas a partir de la privación total o parcial de sobe-

5 A efectos de la concreción del análisis sobre el desarrollo desigual y combinado de un país, no basta solo con el estudio de los niveles del desarrollo interno y sus aspectos tradicionales y modernos, sino también de las características específicas de este último, en función de los paradigmas tecno-económicos del momento y su adecuación a ellos.

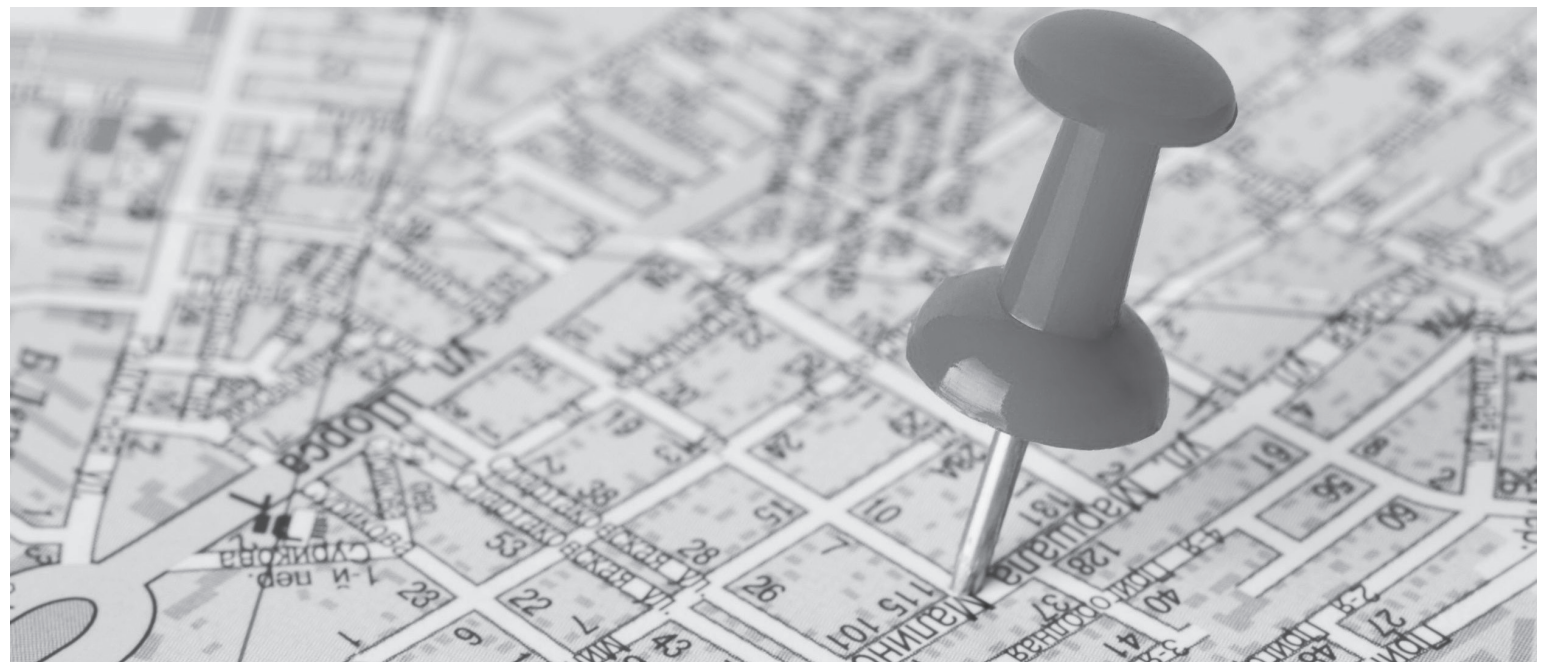


ranía política o colonialismo propiamente dicho, sea este bajo formas completas (coloniales propiamente dichas) o parciales características de las semicolonias (Lenin, 1971; Dabat y Lorenzano, 1982).

B3) Como un aspecto fundamental del Orden Internacional, la inexistencia de un orden estatal mundial conlleva necesariamente el establecimiento de una integración sistémica de los componentes nacionales e internacionales del mismo, a partir de un orden jerárquico impuesto de hecho por la hegemonía mundial, cuasi-mundial o regional de una gran potencia o de una alianza transitoria entre varias de ellas, sin descartar órdenes bipolares de larga data. Las relaciones de hegemonía entre potencias, países y regiones, que además de los vínculos de mercado, supone aspectos como la fortaleza económica, política, cultural, militar y diplomática, el alcance territorial de la relación, las alianzas internacionales o, más recientemente, el control sobre los grandes medios de comunicaciones de masas; y c) el entramado institucional de la organización internacional que van desde las organizaciones interestatales mundiales y regionales a la amplia red de instituciones y organizaciones puntuales, que también expresan relaciones de poder subyacente consistentes con el Orden Mundial.

En cuanto al tipo de relaciones imperialistas o coloniales relevantes, distinguiremos entre distintas formas propias de las cambiantes configuraciones espaciales del sistema (Fieldhouse, 1977: 16-31 y 46-71; Louis 1980: 83 y 219; Dabat 1993: 141-144): a) la colonial del mercantilismo anterior al capitalismo industrial, basado en la dominación comercial y militar propia de los viejos imperios coloniales, de extracción de excedentes económicos mediante la coacción extraeconómica al trabajo servil o esclavo; b) la del imperialismo de libre comer-

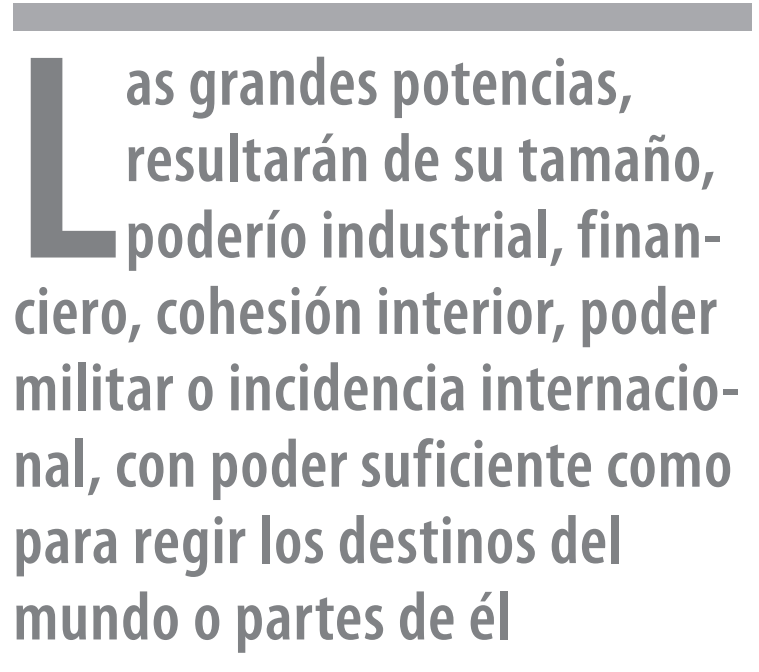

cio pre monopolista, de imposición compulsiva del libre comercio (o cobro de deudas) a países de economía cerrada o semicerrada, sin tratar de modificar sus bases tecno productivas o socio institucionales internas; c) la del "nuevo" imperialismo (o "clásico") de fines del siglo XIX hasta la mitad del xx, propio de la producción industrial masiva y los monopolios modernos, que transforman desigualmente la base productiva y los sistemas socio-institucionales internos de los países sometidos, incorporándolos o no a sistemas coloniales cerrados o semicerrados conforme las características de los mismos y el entorno internacional; d) la del Mundo bipolar de la Guerra Fría partido en torno a dos sistemas sociales e ideológicos contrapuestos (cerrados), con relación a grandes potencias dominantes en competencia económica, social, política y militar, con un "Tercer Mundo" relativamente marginado y e) la de globalización actual, con relativa transnacionalización comercial y financiera, y subordinación de países con base principalmente en el desarrollo tecnológico y la hegemonía globalista de Estados Unidos (EEUU) cada vez más cuestionada por el ascenso chino y de otros países periféricos. 


\section{Dinámica histórica y periodización}

A efectos de la periodización a utilizar, debemos considerar distintos tipos de instrumentos analíticos como: 1) los ciclos u ondas largas de expansión y contracción del sistema (ciclos Kondratieff); 2) los cambios estructurales del sistema a lo largo del tiempo (fases o etapas sucesivas de desarrollo de integración especifica de los distintos planos y componentes del sistema); y 3) las vías alternativas de desarrollo o modalidad direccional del mismo en una determinada etapa el sistema.

(1) La cuestión de los ciclos u ondas largas (o Kondratieff), con sus sucesivos periodos de expansión y declinación relativa, son fundamentales para situar los procesos históricos concretos dentro de la dinámica de largo plazo del capitalismo, siempre que también se los vincule adecuadamente con su alcance territorial. También, para visualizar y comprender las grandes inflexiones de tendencia, que expresan fuertes desacoples entre las esferas productivas, financieras y de regulación pública (grandes crisis sistémicas como las de 1873, 1929, 1974 o 2008) o sus vinculaciones con las guerras y procesos revolucionarios tan propias del periodo que estudiaremos. Por esas razones daremos mucha importancia a la incidencia del ciclo largo sobre los fenómenos históricos y su relación con los factores dinámicos que lo determinan, como son, en primer lugar, las revoluciones tecnológicas y los nuevos paradigmas tecno-productivos resultantes, y sus relaciones con los niveles socio-institucionales del sistema, o su relación con el conflicto sociopolítico con inclusión de las grandes revoluciones y guerras mundiales. ${ }^{6}$

6 Al respecto, puede verse J. Schumpeter 2002; Carlota Pérez, 2004, pps. 48-104; E. Mandel, 1979: pps.106144; J. Rodríguez Vargas, 2005, cap. IV; C. Marichal, 2010; pps. 137-273. Para el tratamiento del ciclo largo
C2) Sobre las etapas o fases del capitalismo, se considera que el desarrollo histórico del sistema se da a partir de una sucesión de discontinuidades estructurales básicas, que dan lugar a cambios sustantivos que afectan a sus diferentes niveles (tecnología, producción, relaciones sociales, instituciones, Estado, cultura) y relaciones de articulación (Dabat, 1993: pps 109-201; y 1994, pps1-30). Para ello, se recogerán las principales contribuciones teóricas e históricas existentes, sea de delimitación secuencial de conjunto, o sobre estudios puntuales de etapas particulares, como las del capitalismo monopolista e imperialista clásico, el fordismo-keynesiano o el capitalismo informático-global actual. ${ }^{7}$ El siglo xx ha vivido cuatro etapas distintas; a) la que arranca a fines del siglo anterior con Segunda Revolución Industrial, el advenimiento del capital monopolistafinanciero y el imperialismo moderna; b) la de las grandes guerras mundiales con el arribo del fordismo en eevu y la Revolución Rusa; c) la que podríamos denominar fordista-keynesiana de la Segunda Postguerra dentro del marco de la Guerra Fría; y d) la actual del Capitalismo Informático-Informal en proceso de declinación por la entrada de la Revolución Informática (RI) en su fase descendente, la declinación de eevu y el acenso internacional de China como gran potencia.

en la perspectiva de la teoría de la economía-mundo y las diferencias de Braudel y Arrighui con Wallerstein, puede verse Ospina (2004).

7 Sobre el punto, además de los trabajos citados, Maddison, 1986; Hobsbawm 2013 y 2013 (secuencia de trabajos); V Lenin, 1948; Hilferding, 1963; Bujarin, 1977; A. Chandler, 1989 (nuevo tipo de gran empresa capitalista); R. Boyer y M. Freissenet, 2001, pps 67-83 (fordismo); Minsky, 1995 (etapas financieras y tecnológicas). También puede verse L. Sandoval, 1980 (Capitalismo monopolista de Estado); J. Whalen, 2001 (relaciones Minsky, Schumpeter y Keynes). 


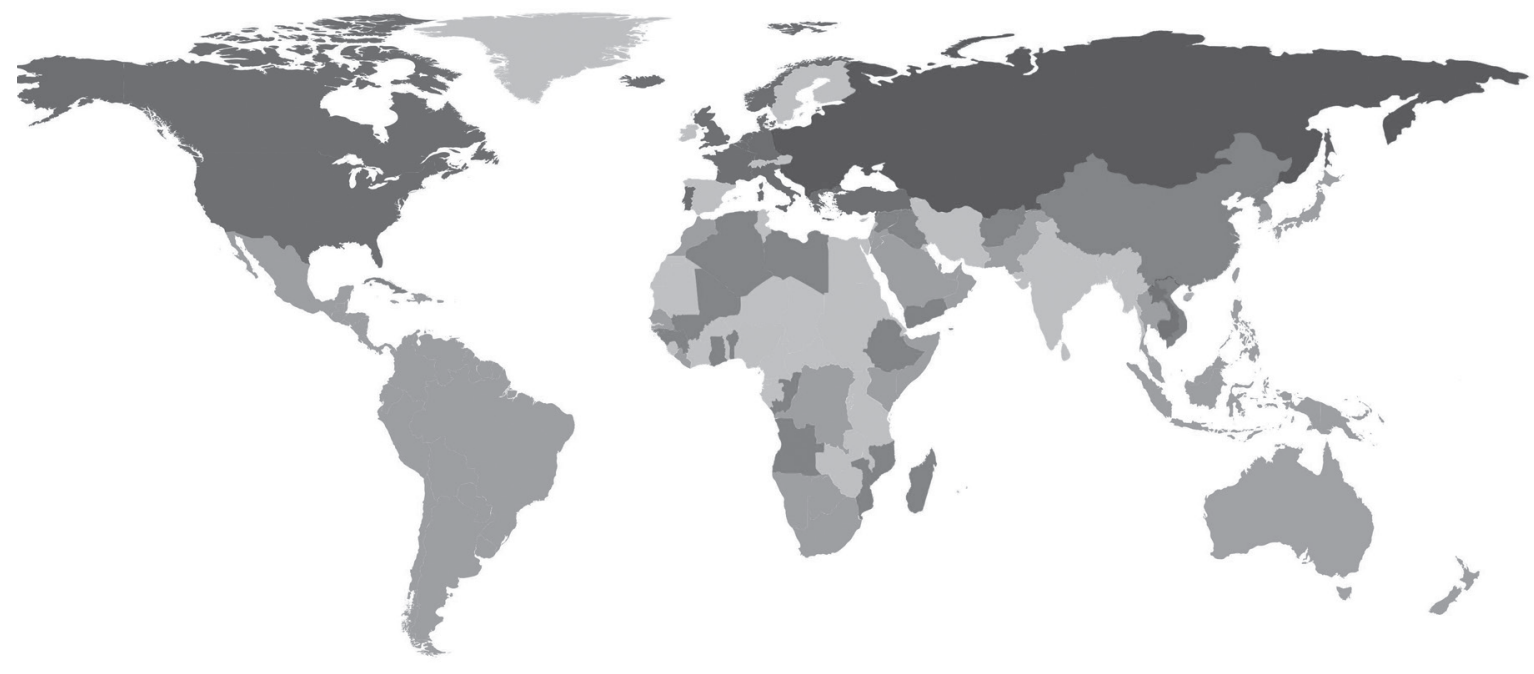

C3) También debe darse mucha importancia a la problemática de las llamadas "vías alternativas de desarrollo", ${ }^{8}$ en cuanto modalidades socio-históricas diferentes que puede adoptar el curso histórico de un país en una época histórica y un espacio territorial determinado, a partir del desenlace de los conflictos sociopolíticos internos, de los distintos proyectos alternativos en juego, de las potencialidades de cambio de ese país y de las presiones contrapuestas entre las clases subalternas desde abajo y de las clases y poderes dominantes desde arriba, dentro de un contexto internacional que también generará fuerzas externas de presión o imposición. Esta cuestión se encuentra directamente ligada a la de los bloques de poder dominantes ("bloques históricos”, según Gramsci) dentro del Estado y la sociedad civil, que es una cuestión que lleva directamente al papel de la lucha política.

8 Este problema esta plateado por Marx y Gramsci en diferentes pasajes de su obra, pero es tomado por también por autores no marxistas, como Barrington Moore en obra clásica "Orígenes sociales de la dictadura y la Democracia (1966). Para un desarrollo de este concepto puede verse Dabat, El Mundo y las Naciones I, Introducción.

\section{Prácticas y conflictos sociales}

D1) Por prácticas sociales, debemos entender la actividad (praxis) de colectivos sociales en un plano determinado, o en un conjunto entrelazado de ellos, basadas en intereses y objetivos comunes que sobredeterminan el papel de los individuos participantes y tienden a arrastrarlos a ellos consciente o inconscientemente, por obra de múltiples factores objetivos y subjetivos. En principio, existen prácticas sociales propias de cada plano constitutivo del sistema, de su base histórica-especial y de sus niveles de amplitud y organización. La existencia de estas prácticas sociales, el elemento colectivo de las mismas no excluye al papel del individuo o grupos de individuos aislados, sino que los integra en ellas, a partir del papel consciente o inconsciente que cumplen dentro de las prácticas sociales. ${ }^{9}$ Esta concepción se opone

9 Al respecto es muy importante el trabajo de Plejanov sobre el papel del individuo en la historia (Plejanov, Obras Competas, I, 1964), que, aunque peca de cierto determinismo, plantea correctamente la cuestión central (que los movimientos históricos requieren de cierto tipo de individuos, y que estos no pueden generar por sí mismo grandes movimiento y cambios 
directamente a las teorías propias del invidualismo neoliberal, que conciben a lo que llaman acción colectiva, como simple sumaria de individuos independientes movidos por interés exclusivamente propios.

D2) Las prácticas sociales colectivas se convierten en movimientos sociales cuando adoptan objetivos y formas organizacionales propias. Conforme su relación con las instituciones sociales establecidas, su conformación de poder y la manera en que ellas respondan a las necesidades de su base social, pueden adoptar la forma de movimientos sociales defensivos, de reformas institucionales menores, o de búsqueda de transformación de fondo de dichas instituciones, cuando estas han dejado de corresponder a los intereses de la comunidad que constituye su base de sustentación y más bien se convierten en un obstáculo para su desarrollo y en una fuente de destrucción en una etapa determinada de desarrollo. Este es actualmente el caso de los países y los pueblos subordinados al orden mundial neoliberal y belicistas que ha provocado una enorme catástrofe social y demográfica en la gran mayoría de los países del mundo y a una acumulación de cuantiosas fortunas ociosas y especulativas en un puñado de enormes potentados. Cuando este tipo de conflicto se da al nivel de Estado y su relación con el pueblo-nación y las clases subalternas, se pasa al nivel de la lucha política.

D3) La lucha política dentro de un Estado determinado puede adquirir diferentes formas: a) Cambios menores que no alteran las relaciones sociales (por ejemplo, reformas económicas, sociales o culturales puntuales); b) de cambio de fondo de la institucionalidad estatal a través de la lucha política y la confrontación de diferentes bloques de poder. Esto última implica necesariamente una participación popular di-

históricos si no existen condiciones históricas (económicas, sociales y culturales para ello). recta de mayor o menor amplitud, en las que será fundamental la relación existente entre la participación directa de las clases subalternas y las fuerzas políticas que solo representen muy parcialmente sus intereses, o que incluso pueden adquirir la forma de lo que Gramsci llamara "revolución pasiva". La fuerza del movimiento político social de las clases subalternas ante la intransigencia de las instituciones y las relaciones establecidas, puede elevar la confrontación política a un nivel incompatible con la institucionalidad clasista establecida, dando lugar, ya sea a grandes procesos de cambio por medios cívico-institucionales o a guerras civiles que pueden adquirir diferentes formas como es la toma del poder por los trabajadores y el pueblo (caso de la insurrección que dio lugar a la Revolución rusa), que es un medio muy difícil de repetir en las actuales condiciones históricas dada la disgregación de la clase obrera. De manera similar a lo anterior, también pueden surgir golpes de Estado contrarrevolucionarios militares o, más bien, actualmente, institucionales; o a su contrario (en los pocos países que cuentan con ejércitos progresistas) ${ }^{10}$, guerras civiles prolongadas, como la que condujo al triunfo en su época a las revoluciones china o cubana o, como es mucho más común hoy día la utilización de medios electorales para acceder el poder.

\section{E. Las guerras internacionales y mundiales}

E1) En general, la guerra es una actividad destructiva de vidas y de fundamentos materiales y culturales de la vida humana que afecta en

10 Este sería en América Latina, por ejemplo, los golpes de Estado de Getulio Vargas en Brasil en 1937, del Perón y Edelmiro Farell en 1943 o del intentado por Chávez en Venezuela en 1982. Fuera de América Latina, sería el caso de la Revolución de los Claveles en Portugal en 1974 o de la llamada "Revolución de Saur" de 1978 que inició la guerra afgana de 1978 que terminaría sentando las bases para la creación Al Qaeda. 


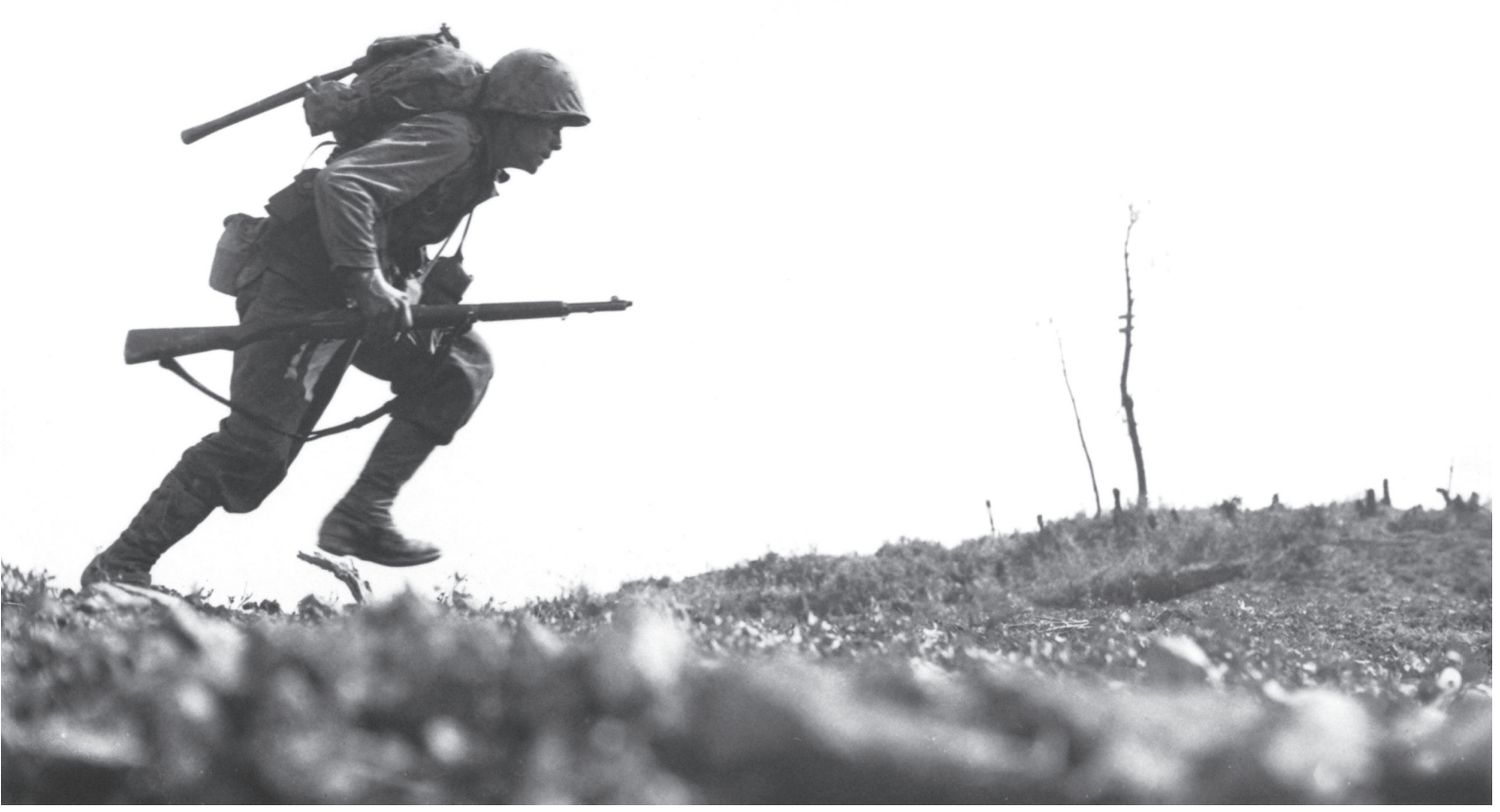

principalmente al derrotado, pero no solo a él, También resulta destructiva la preparación y desenvolvimiento de la guerra, en cuanto uso parasitario de recursos humanos, conocimientos y excedentes económicos factibles de otros usos socialmente útiles. En ese sentido (a pesar de los grandes logros temporales que puede obtener), la guerra terminará por afectar a largo plazo a las potencias militares, ante los países que usan más productivamente sus recursos a lo largo de la historia. Por ello, las Guerras Mundiales de 1913-19 y de 1945-49 significarían enormes catástrofes sociales que, por esa razón, favorecerían el triunfo de la Revolución Rusa de 1917 o de la Revolución China de 1949, así como constituirán las bases a largo plazo (tras el agotamiento del Estados del Bienestar) para el progresivo declive de Europa Occidental y el ascenso de EeuU y Rusia.

E2) Junto al concepto de guerra como confrontación armada (o guerra "caliente" en sentido metafórico), el siglo $\mathrm{xx}$ incorporara otro concepto de guerra (la "Guerra Fría"), resultante tanto del enorme desarrollo tecnológico de la capacidad de exterminios masivos de población (armas nucleares), como de la paridad relativa de fuerzas entre los contendientes, abriendo así paso al concepto de guerras limitadas, de capacidad militar disuasiva y de otras formas de destrucción o contención del enemigo, por medios diferentes al de la utilización de armas mortales, como serán las posibilitadas por la nueva tecnología informática a la que ya nos referiremos, o al uso de los golpes de Estado "blandos" contra los gobiernos progresistas. Habría que agregar que en las nuevas condiciones históricas caracterizadas por la descomposición del capitalismo neoliberal y la aparición de "Estados Fallidos" y agravamiento de la extrema pobreza en las áreas más afectadas del mundo, han aparecido un nuevo tipo como las generadas por el Yihadismo o por la delincuencia trasnacional organizada. ${ }^{11}$

E3) En concreto, debe partirse del hecho de no todas las guerras son iguales. En esencia, la guerra es una "continuación de la política

11 Entro otros muchos trabajos al respecto, ver Verónica Sánchez, Influencias de las guerras criminales de carácter trasnacional en los conflictos (2016). 
por otros medios" 12 , lo que vincula la naturaleza específica de cada guerra a la naturaleza de los conflictos subyacentes que la determinan e inciden en ella. Por su alcance territorial y contenido, serán tanto guerras internacionales, regionales, mundiales o civiles, como convencionales y sociales; pero en todo caso, será siempre fundamental la participación de los pueblos involucrados, sea combatiendo en ejércitos convencionales, en guerrillas, en resistencia civil ante invasores ${ }^{13}$ o en respuesta a planes de políticas de "ajuste" como los latinoamericanos. La capacidad de resistencia de la población ante la incomparable superioridad militar quedaría plenamente demostrada tanto en la Guerra de Vietnam, en la resistencia Palestina o las actuales guerras de Irak y Siria; pero también en la resistencia a las políticas de marginación social de las mayorías populares en distintas partes del mundo.

E4) El desenlace de una guerra moderna, depende de la fuerza militar y de recursos de los protagonistas (ver punto B1), pero también de la capacidad de lucha y resistencia de los pueblos y de su capacidad para desencadenar "guerras irregulares" defensivas. En última instancia, los logros bélicos, pueden resultar mucho menos importantes que los efectos negativos más amplios de los mismos, sea por la incapacidad del vencedor para imponer su triunfo en la posguerra ${ }^{14}$, como por las con-

12 Carl Von Clausewitz, On War, vol. 1 Colonel J.J. Graham, The Project Gutenberg E-Book, 2006 p. 14-23.

13 La dirección militar es pues, una cuestión más amplia que la dirección propiamente dicho; la determinación del plan estratégico que este ejército debe desarrollar concierne a la determinación de las fuerzas populares que se alcen a espaldas del enemigo y obstaculicen su movimiento, tiendan a crear masas auxiliares y de reserva, de las que se pueden extraer nuevos ejércitos y que den al ejército "técnico" la atmósfera de entusiasmo y ardor" (Gramsci, 1975)

14 Al respecto, resulta ilustrativo el análisis de los "triun- a capacidad de resistencia de la población ante la incomparable superioridad militar quedaría plenamente demostrada tanto en la Guerra de Vietnam, en la resistencia Palestina o las actuales guerras de Irak y Siria

secuencias económicas, sociales y políticas internas ("pírricas") para el país supuestamente vencedor, como sería el caso de las guerras desatadas en Medio Oriente por las invasiones estadounidenses de Afganistán e Irak, que concluirían en una tremenda derrota y retirada de las fuerzas invasoras.

E5) Actualmente, la revolución informática, la globalización y la financiarización de la economía mundial, se ha conjuntado con la declinación de Estado Unidos (agotamiento de la primera fase de la revolución informática, neoliberalismo, crisis financiera mundial centrada en ese país y derrotas en Medio Oriente) y el ascenso de China, la Rusia de Putin, Irán y otros países del mundo (entre los que destacó hasta hace muy poco América del Sur) y el ascenso de las fuerzas populares y democráticos en La Unión Europea y Estados Unidos. Esto está polarizando al mundo en dos grandes agrupamientos mundiales tendenciales que están llevando a una "Segunda Guerra Fría” y

fos militares" recientes de EEUU en Irak o Afganistán, J. Stiglitz, y L. Bilmes, La guerra de los tres billones de dólares (trad. A. Pradera y N. Ruiz de la Prada, México, Taurus, 2008, cap. 1) o, anteriormente, en Vietnam, tanto para los "vencidos" como para los "vencedores". 
plantean la posibilidad (aunque improbable) de una tercera Guerra Mundial "caliente". Pero esto se dará dentro de un nuevo contexto bélico de guerras internacionales a distancia, en el que la guerra en sentido tradicional basada en la destrucción de las fuerzas armadas enemigas combatiendo en un territorio determinado, da lugar a un nuevo tipo de guerra "no convencional”, básicamente a distancia apelando a las nuevas tecnologías informáticas, espaciales y de inteligencia, con muy poco envío de combatientes al exterior. Este tipo de guerra o "guerra de cuarta generación" 15 , cuyo objetivo fundamental, no es tanto ocupar el territorio del enemigo, sino más bien desestabilizarlo y debilitarlo (como afectar a sus infraestructura física o informacional o a su capacidad financiera), sin enviar a la guerra a grandes contingentes de población nacional. Dentro de esta nueva concepción pasaran a tener gran importancia la llamada ciber-guerra, muy vinculado al concepto más puntual de "golpe de Estado blando" o también "Revoluciones de Colores", para derrocar a los gobiernos hostiles. ${ }^{16}$

\section{F. Una visión prospectiva de las vías de desarro- llo alternativo}

Con base a lo expuesto podríamos apuntar a un conjunto de hipótesis preliminares para la discusión de los sectores progresistas, la que además debe de incluir el análisis prospectivo en torno a las posibles vías de desarrollo que nos depara la actual situación del mundo.

15 El concepto de guerra de "cuarta generación" se basa en lo fundamental en la combinación de viejos instrumentos bélicos, con otros como los informáticos, las acciones encubiertas o las operaciones de inteligencia conforme fuera teorizado inicialmente por Van Crebel (La transformación de la guerra, 1991) y asumiera plenamente en Estados Unidos con posterioridad el presidente Obama.

16 Ver diversos trabajos de Thierre Messan al respecto.
F1) El sistema capitalista está atravesando por una de sus mayores crisis como consecuencia del agotamiento de una etapa del capitalismo producto, en última instancia del agotamiento del ciclo tecnológico ascendente generado por la revolución informática, que se ha desviado cada vez más de sus grandes logros tecnológicos genéricos (para el conjunto de la economía y la vida social) a una abrumadora variedad de gadgtes para los ricos y la clase media acomodada.

F2) Que, en términos del espacio mundial, el mundo está viviendo un gran reacomodamiento territorial en favor de Eurasia encabezada por China y de los países del ex Tercer mundo que logran desembarazarse de las cadenas del neoliberalismo, en detrimento de la potencia hegemónica mundial (EEUU en plena declinación y de la Unión Europea. Pero que esto va acompañado desgraciadamente por una gran cantidad de los llamados Estados fallidos dominados por el hambre, la enfermedad y la delincuencia internacional.

F3) Que este abre la posibilidad de tres vías de desarrollo: ${ }^{17}$ a) la continuidad de la neoliberal a costo cada vez mayores para la humanidad (económicos, sociales, culturales y ambientales); b) el triunfo de la vida estatistaproductivista desde arriba posibilitará mejores resultado económicos y sociales para el mundo y uso más útiles de la tecnología para la vida humana, aunque a costos de autoritarismos e importantes carencias de derechos humanos; y c) la construcción de un mundo más solidario, democrático y responsable con el medio am-

17 El concepto de vías alternativas de desarrollo fue originalmente planteado por Marx en diversos pasajes de "El Capital" y retomado por Gramsci. Pero también es utilizado por autores no marxistas como Barrington Moore en su obra clásica Los orígenes de la dictadura y la democracia (1976) y desarrollado por Dabat en la introducción de Capitalismo mundial y capitalismos nacionales I. (1993) 
biente impulsado desde abajo por la lucha de los pueblos y los sectores más progresistas de la sociedad mundial.

F4) Sin embargo, a corto y mediano plazo, el futuro dependerá de la pugna entre el eje chino-ruso de economía mixta social productivista vs las economías neoliberales, especuladoras y derrochistas de Occidente, en la que la primera tiene todas las posibilidades históricas de ganar, contando con el respaldo crítico de los intelectuales, fuerzas progresistas y sectores subalternos de la población mundial. Esto obedece a que aún la tercera vía (democrática, inclusiva y solidaria desde la base de la sociedad), carece aún de posibilidades de imponerse a nivel mundial. Pero la lucha contra el del neoliberalismo y el desarrollo de la producción, el empleo, la educación y la tecnología en el mundo, permitirá la maduración de las fuerzas componentes de la tercera alternativa, mediante la acumulación de fuerzas cognitivas, organizacionales y volitivas en la lucha por la derrota del actual orden neoliberal junto, pero independientemente, con las fuerzas de la segunda vía, abriendo así las posibilidades del mundo más solidario, democrático y sustentable como señaláremos.

\section{Bibliografía}

ACNuR, [2014]; Tendencias Globales, desplazamiento forzado en 2014. Disponible en: http://www.acnur.org/t3/fileadmin/Documentos/Publicaciones/2015/10072.pdf?view

Adams, Jr., R. H. [2003]; International Migration, Remittances, and the Brain Drain: A Study of 24 Labor-Exporting Countries. World Bank Policy Research

Ahmed, N. [2014], "Pentagon preparing for mass civil breakdown." En The Guardian. Disponible en línea: https://www.theguardian.com/environment/earth-insight/2014/jun/12/pentagon-mass- civil-breakdown. Consultado: 15 de junio de 2015. Amnistía Internacional, [2017]. Informe Anual 2016/17 de Amnistía Internacional. Disponible en línea: https://www.amnesty.org/es/latest/ news/2017/02/amnesty-international-annual-report-201617/. Consultado: 6 de mayo de 2017.

Aragonés, A. M y Rubio, R. [coords.] [2009]. Nuevas causas de la migración en México en el contexto de la globalización: tendencias y perspectivas a inicios del nuevo siglo, México, unam, Fes-Acatlán y Plaza y Valdés

BaKer, Monya [2013], "Violence against Women at Epidemic Proportiones", Nature Magazine, june 20, y Scientific American https//www.scientificamerican/violence-agaist-women-at-epidemic-proportions

BOYeR, R. [2007]. Crisis y regimenes de crecimiento: una introducción a la teoría de la regulación. Miño y Dávila.

Сномsку, Noam [2007]. Estados Fallidos: el abuso de poder y el ataque a la democracia. Barcelona: Ediciones $\mathrm{B}$

Dabat, A. [1993]. El mundo y las naciones, México, CRIM-Unam.

Dават, A, Rivera M. Á. y S. Sztulwark [2009]. "Rentas económicas globales, desarrollo y capacidad organizacional. Implicaciones para América Latina” en Basave, J. y Rivera [Coord.], Globalización, conocimiento y desarrollo, Tomo 2. México, unam.

Dabat, A, Leal, P y S. Romo [2012]. "Crisis mundial, agotamiento del neoliberalismo y de la hegemonía norteamericana: contexto internacional y consecuencias para México", Norteamérica, unAM, 7 [2], pp. 75-110.

El PAís [2014], China refuerza su influencia económica en Afganistán http://internacional. elpais.com/internacional/2014/10/31/actualidad/1414774479_628939.html

Figueroa, I. y Cordero, C. [2011], Posneoliberalismo en América Latina. Los limites de la hegemonía neoliberal en la región, México, Porrúa.

IbARRA, D. [2013]. "La erosión del orden neoliberal del 


\section{ECONOMÍA INFORMA | 407 | NOVIEMBRE-DICIEMBRE 2017 |}

mundo" en Economía-UNAM, Vol. 10 [29].

López, Ana [2011] Los Estados "fallidos" y sus implicaciones en el ordenamiento juridico internacional. En Cursos de Derecho Internacional y Relaciones Internacionales de Vitoria-Gasteiz 2010. Servicio editorial de la Universidad del País Vasco, Bilbao, pp. 159-240.

Martín, O. M. [2005]. África, el continente maltratado: guerra, expolio e intervención internacional en el África Negra. Cristianisme i Justícia.

McCurry [2016] Half a million South Koreans celebrate impeaching of president Park Geun-hye. Disponible en línea: https:/www.theguardian.com/ world/2016/dec/12/half-a-million-south-koreanscelebrate-impeaching-of-president-park-geun-hye. Consultado: 12 enero 2017.

Moore, Barrington [1976], Los orígenes sociales de la dictadura y de la democracia: El señor y el campesino en la formación del mundo moderno. Traducción Jaime Acosta y Gabrielle Woith, Barcelona, Ed. Península

Mokнoff, N. [2012]. "Semi Industry Fab Costs Limit Industry Growth.” EE Times.

OMs [2014] Informe sobre la situación mundial de las enfermedades no transmisibles 2014. Disponible en línea: http://apps.who.int/iris/ bitstream/10665/149296/1/WHO_NMH_ NVI_15.1_spa.pdf?ua=1\&ua=1. Último acceso: 23 septiembre 2016.

Piketty, T. [2014], El capital en el siglo XXI, México, FCE.

Prieto, M. [2017] Moon Jae-In, el otro problema coreano de Estados Unidos en El Mundo. Disponible en línea: http://www.elmundo.es/internacional/ 2017/05/04/59085bf1ca47418e248b45c3.html. Consultado. 10 de agosto de 2017.

Ramírez y Molina, 2001, "Las guerras olvidadas." En La Jornada. Disponible en línea: http://www. jornada.unam.mx/2001/09/30/mas-guerras.html. Consultado: 4 de agosto de 2016.

Roubini, N. y Mihm, S. [2010], Cómo salimos de esta. Chile, Destino.

Sader, E. [2011], Posneoliberalismo en América Latina, Buenos Aires, Clacso

Stiglitz, J. [2006], Cómo hacer que funcione la globalización, Argentina, Taurus.

Stiglitz, J. [2010b]. El malestar en la globalización. México, Taurus.

Stiglitz, J. \& Bilmes, L. [2008], La guerra de los tres billones de dólares, México, Taurus.

Stiglitz, J. [2012], El precio de la desigualdad, México, Taurus.

Symonds, Peter [2011], "La rivalidad entre Estados Unidos y China alimenta la tensión en Tailandia”, Ojos del Mundo, 2 de julio.

The Guardian [2016]. Trial opens of 'Rasputin' at heart of South Korea political crisis. Disponible en línea: https://www.theguardian.com/world/2016/ dec/19/choi-soon-sil-trial-rasputin-park-geun-hye. Ultimo acceso: 2 de febrero de 2016.

un News Centre, [2014]. 'War's Human Cost': World's population of displaced tops 50 million, UN refugee agency reports. Disponible en línea: http://www. un.org/apps/news/story.asp? NewsID =48089\#. WcLfZ8jyjIU. Consultado: 12 de junio 2016.

World ECONOMIC Forum [WeF], [2015]. ¿Es el capitalismo la causa de la pobreza? 21 de agosto. Disponible en línea: https://www.weforum.org/es/ agenda/2015/08/es-el-capitalismo-la-causa-de-lapobreza/. Consultado: 2 de junio de 2016.

Yuan, J. [2006]. China-ASEAN relations: Perspectives, prospects and implications for US interests. Strategic Studies Institute, US Army War College. Disponible en: https://ssi.armywarcollege.edu/pdffiles/PUB735.pdf. Consultado: 20 febrero 2016 